\title{
A POSITRON EMISSION TOMOGRAPHY STUDY OF VOLUNTARILY AND ELECTRICALLY CONTRACTED HUMAN QUADRICEPS
}

\author{
MARC VANDERTHOMMEN, PhD, * JEAN-CLAUDE DEPRESSEUX, MD, PhD, \\ PHILIPPE BAUVIR, PT, CHRISTIAN DEGUELDRE, PhD, GUY DELFIORE, PhD, \\ JEAN-MARIE PETERS, PhD, FRANCIS SLUSE, PhD, and \\ JEAN-MICHEL CRIELAARD, MD, PhD
}

Department of Physical Medicine, Cyclotron Research Centre, University of Liège, Liege, Belgium

Accepted 1 October 1996

Within the domain of physical therapy, it has been proposed that electrical stimulation programs might be beneficial toward minimizing both muscular atrophy and loss of oxidative capacity as a result of patient immobilization. ${ }^{5}$

Within the fundamental research field, most authors assess biochemical parameters in stimulated human muscle via biopsies ${ }^{3,8}$ or ${ }^{31} \mathrm{P}$ nuclear magnetic resonance (NMR) techniques, ${ }^{12}$ but little is known about the muscular blood flow and the local aerobic metabolism in the electrostimulated human muscle.

The possibility to evaluate muscular blood flow (MBF) and muscular metabolic rate of oxygen $\left(\mathrm{MMRO}_{2}\right)$ by positron emission tomography (PET) and ${ }^{15}$ oxygen-labeled tracers was first described in the study of the human brain. ${ }^{6}$

We applied an adapted version of the bolus technique $^{4}$ allowing us to investigate the local MBF and $\mathrm{MMRO}_{2}$ in electrically stimulated (ES) and voluntarily contracted (VC) quadriceps of healthy human subjects.

\section{METHODS}

Eight healthy male volunteers [22.5 $\pm 3.3(\mathrm{SD})$ years] first underwent an evaluation to determine the maxi-

${ }^{*}$ Correspondence to: Dr. Marc Vanderthommen

CCC 0148-639X/97/040505-03

(c) 1997 John Wiley \& Sons, Inc. mum isometric voluntary torque (MIVT) from each quadriceps.

Then, MBF and $\mathrm{MMRO}_{2}$ were evaluated by PET during a bilateral simultaneous isometric exercise, using ES (three excitative electrodes; pulse frequency $=50 \mathrm{~Hz}$; pulse width $=0.25 \mathrm{~ms}$ ) on one quadriceps and VC for the other. Except for the contraction mode, the exercise protocol remained unchanged for each quadriceps. The subjects were submitted to bilateral contraction (5.5 s)-rest (5.5 s) cycles for $12 \mathrm{~min}$, with a workload corresponding to $20 \%$ of MIVT.

Blood Flow Study. A bolus injection of $80 \mathrm{mCi}$ of $\mathrm{H}_{2}{ }^{15} \mathrm{O}$ in the right forearm was administered. Emission data were acquired during the 4 min between the 8 th and 12th min of exercise.

Data from arterial blood counting $(240 \times 1 \mathrm{~s})$ and tomograms $(20 \times 12 \mathrm{~s} ; 512 \times 512$ pixels; 30 slices) (ECAT-II 951, Siemens) were processed using a system of simultaneous linear equations.

Six circular regions of interest, $2 \mathrm{~cm}$ in diameter, were selected in each quadriceps. Superficial regions were located in the vastus medialis (\#1), rectus femoris (\# 2), and vastus lateralis (\# 3) with the central point at $2.5 \mathrm{~cm}$ from the skin surface. Deep regions (\# 4,5,6) were selected below the three superficial regions with the central point at $5 \mathrm{~cm}$ from the skin surface.

Oxygen Consumption Study. During another procedure, 60 min after the injection of $\mathrm{H}_{2}{ }^{15} \mathrm{O}$, the subjects 
inhaled three vital capacity breaths of ${ }^{15} \mathrm{O}_{2}$ from an air bag containing $80 \mathrm{mCi}$ of tracer.

Data were also acquired during the 4 min between the 8th and the 12th min of the same exercise protocol.

The $\mathrm{MMRO}_{2}$ values $\left(\mathrm{mL} \mathrm{O}_{2} \cdot \mathrm{min}^{-1} \cdot 100 \mathrm{~g}^{-1}\right)$ were computed as the product of local MBF, muscular oxygen extraction rate, and systemic arterial blood oxygen content. The same regions of interest were used for $\mathrm{MBF}$ and $\mathrm{MMRO}_{2}$ evaluation.

\section{RESULTS}

Figure 1 shows the mean values of $\mathrm{MBF}$ and $\mathrm{MMRO}_{2}$ for the six regions of interest during exercise in the voluntarily and electrically contracted quadriceps.

The overall values were significantly lower $(P<$ 0.001 ) in the voluntarily contracted quadriceps than in the electrically contracted quadriceps for $\mathrm{MBF}$ $\left(8.6 \pm 3.6\right.$ vs. $\left.24.4 \pm 14.6 \mathrm{~mL} \cdot \mathrm{min}^{-1} \cdot 100 \mathrm{~g}^{-1}\right)$ and $\mathrm{MMRO}_{2}\left(0.72 \pm 0.34\right.$ vs. $3.01 \pm 2.3 \mathrm{~mL} \mathrm{O} \cdot \mathrm{min}^{-1}$ $\left.100 \mathrm{~g}^{-1}\right)$.

In the voluntarily contracted quadriceps, mean values were significantly lower in superficial (\# 1, 2, and 3 ) versus deep (\# 4,5, and 6 ) regions of interest $(P<0.001)$ for both MBF $(6.5 \pm 2.3$ vs. $10.6 \pm 4.1$ $\left.\mathrm{mL} \cdot \mathrm{min}^{-1} \cdot 100 \mathrm{~g}^{-1}\right)$ and $\mathrm{MMRO}_{2}(0.58 \pm 0.27$ vs. $\left.0.87 \pm 0.45 \mathrm{~mL} \mathrm{O} \mathrm{O}_{2} \cdot \min ^{-1} \cdot 100 \mathrm{~g}^{-1}\right)$. In the stimulated quadriceps, the superficial regions show markedly higher mean values $(P<0.001)$ than in deep regions, for $\mathrm{MBF}(36.2 \pm 6.0$ vs. $12.6 \pm 6.8$ $\left.\mathrm{mL} \cdot \mathrm{min}^{-1} \cdot 100 \mathrm{~g}^{-1}\right)$ and $\mathrm{MMRO}_{2}(4.94 \pm 1.54$ vs. $\left.1.07 \pm 1.01 \mathrm{~mL} \mathrm{O}_{2} \cdot \mathrm{min}^{-1} \cdot 100 \mathrm{~g}^{-1}\right)$.

\section{DISCUSSION}

Higher blood flow and oxygen consumption are induced by tetanic electrical stimulation than that during a similar exercise protocol utilizing voluntary contractions.

This effect could be the result of several additional events in the pattern of muscle contractile activity.

Initially, ES induces a continuous and exhausting contractile activity in the same pool of motor units during the entire exercise period, whereas the nervous system regularly adapts the recruitment of motor units during the exertion. ${ }^{2}$

Second, the stimulation frequency $(50 \mathrm{~Hz})$, chosen for its mechanical efficiency ${ }^{16}$ corresponds to the maximum spontaneous discharge frequency of not only type II motor units, ${ }^{7}$ but to an even greater degree of the type I motor units which discharge spontaneously at lower frequency. ${ }^{17}$ Thus, the $50-\mathrm{Hz}$
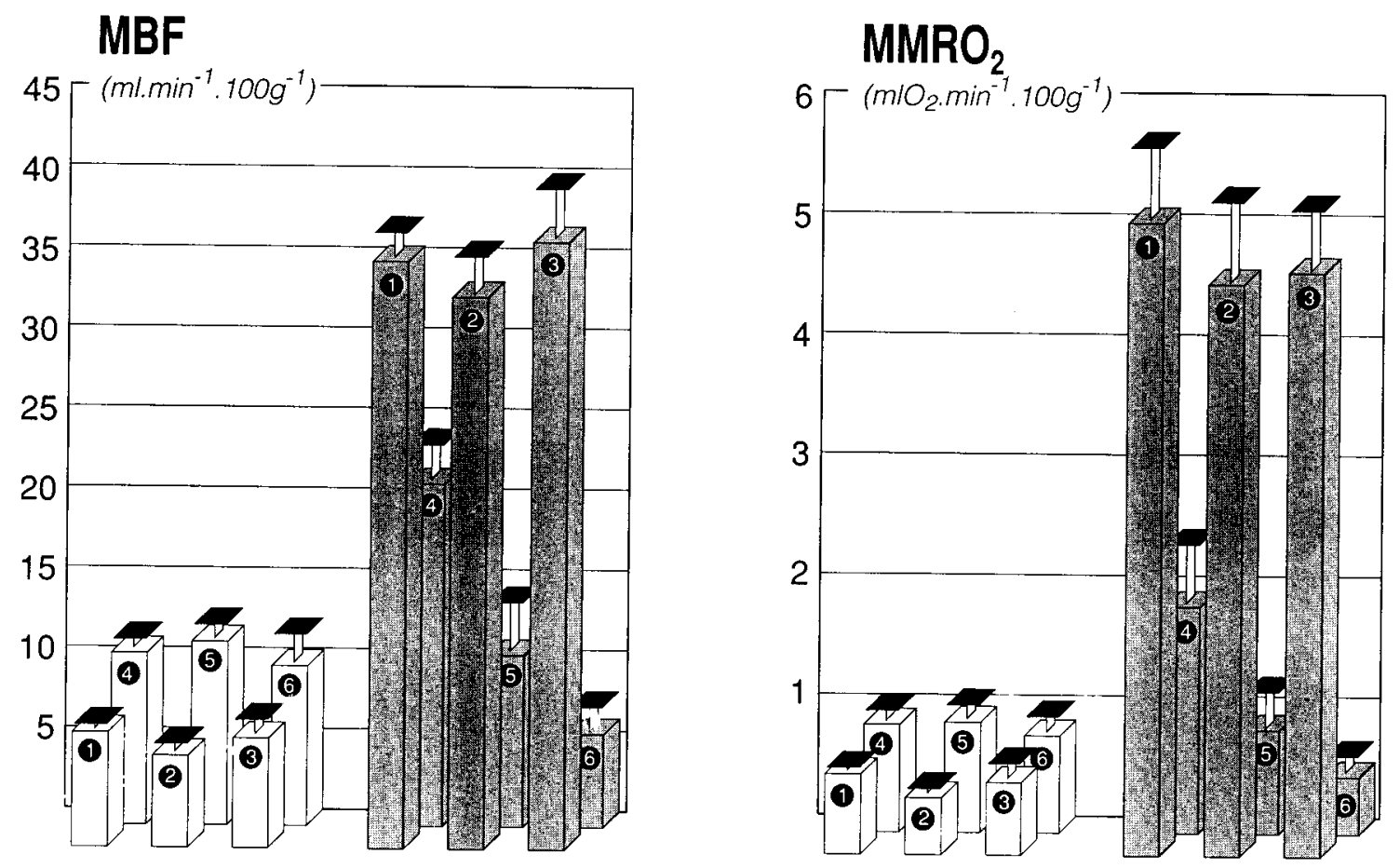

FIGURE 1. Muscular blood flow (MBF) $\left(\mathrm{mL} \cdot \mathrm{min}^{-1} \cdot 100 \mathrm{~g}^{-1}\right)$ and muscular metabolic rate of oxygen $\left(\mathrm{MMRO}_{2}\right)\left(\mathrm{mL} \mathrm{O}_{2} \cdot \mathrm{min}^{-1} \cdot 100 \mathrm{~g}^{-1}\right)$ at rest and during exercise in superficial $(1,2$, and 3$)$ and deep $(4,5$, and 6$)$ regions of interest in voluntarily ( $\square)$ and electrically $(\mathbf{\square})$ contracted quadriceps (means $+\mathrm{SD}, n=8$ ). 
frequency imposes on the activated motor units a supramaximum temporal recruitment.

Third, the skeletal muscle is activated in an asynchronous manner during voluntary efforts when electrical stimulation synchronously recruits the different motoneuron branches. ${ }^{1}$

Fourth, ES leads to a maximal tetanic contractile activity in neighboring fibers. This concentrated activity most likely induces a local capillary collapse that reduces oxygen supply during the contraction phases..$^{13}$ Thus, metabolites liberated during contraction progressively involve a local vasodilatation ${ }^{9}$ and an increase in local blood flow and oxygen supply during the periods between contractions.

Therefore, as suggested by Adams and coworkers, ${ }^{1}$ it seems probable that, in some regions of the quadriceps, ES was responsible for an exaggerated metabolic demand for the required force development, thereby resulting in high level of MBF and $\mathrm{MMRO}_{2}$.

Voluntary contraction specifically recruits deep motor units in the quadriceps. This result could lead to the following interpretation: at this low level of isometric exercise ( $20 \%$ of MIVT), the intentionally contracted muscle recruits only type I fibers. ${ }^{14}$ This recruitment applies a specific solicitation of deep quadriceps regions. In fact, there is evidence suggesting that type I fibers are preferentially located in deep regions of the quadriceps. ${ }^{11}$

Percutaneous stimulation pulses cause a particular spatial recruitment of human quadriceps. If some deep parts of the muscles are activated, the pattern of muscle stimulation shown in this study is clearly superficial. This recruitment probably rests on the principle of cutaneous ES and on the location of motoneuron branches; the branches situated at the surface below the electrodes are preferentially depolarized, while those located deep within the muscle tissue become involved only as the current strength increases. ${ }^{10}$

Electrical stimulation caused an exaggerated metabolic demand in superficial regions of the quadriceps, resulting in a high level of blood flow and oxygen consumption. This major metabolic demand could explain the efficiency of electrical stimulations to improve the muscle torque during a prolonged bedside confinement or during a segmentary immobilization. ${ }^{15}$

\section{REFERENCES}

1. Adams GR, Harris RT, Woodard D, Dudley GA: Mapping of electrical muscle stimulation using MRI. J Appl Physiol 1993;74:532-537.

2. Astrand PO, Rodhal K: Manuel de Physiologie de l'Exercise Musculaire. Paris, Masson, 1980, pp 75-91.

3. Constantin-Teodosiu D, Cederblad G, Hultman E: PDC activity and acetyl group accumulation in skeletal muscle during isometric contraction. J Appl Physiol 1993;74:1712-1718.

4. Depresseux JC, Cheslet JP, Franck G: An original method for the concomitant tomographic assessment of cerebral blood flow, oxygen extraction rate, and blood volume exchangeable water volume in man. J Cereb Blood Flow Metab 1983;3:152153.

5. Eriksson E, Häggmark T: Comparison of isometric muscle training and electrical stimulation supplementing isometric muscle training in the recovery after major knee ligament surgery. Am J Sports Med 1979;7:169-171.

6. Frackowiak RS, Lenzi G, Jones T, Heather JD: Quantitative measurement of regional cerebral blood flow and oxygen metabolism in man using 15-0 and positron emission tomography. J Comput Assist Tomogr 1980;4:727-736.

7. Hannerz J: Discharge properties of motor units in relation to recruitment order in voluntary contraction. Acta Physiol Scand 1974;91:374-384

8. Hultman E, Spriet LL: Skeletal muscle metabolism, contraction force and glycogen utilization during prolonged electrical stimulation in humans. J Physiol 1986;374:493-501.

9. Kjellmer I: Studies on exercise hyperemia. Acta Physiol Scand 1965;64:244.

10. Lambert H, De Bisschop F, De Mey G, De Cuyper H, Demurie S, Vanderstraeten G, Blonde W: Calculation of electric current distribution in tissue. Eur J Phys Med Rehabil 1991;1:126132.

11. Lexell J, Henriksson-Larsen K, Sjöström M: Distribution of different fibre types in human skeletal muscles. Acta Physiol Scand 1983;177:115-122.

12. Matheson GO, McKenzie DC, Gheorghiu D, Ellinger DC, Quinney HA, Allen PS: ${ }^{31} \mathrm{P}$ NMR of electrically stimulated rectus femoris muscle: an in vivo graded exercise model. Magn Reson Med 1992;26:60-70.

13. Metzger JM, Fitts RH: Fatigue from high- and low-frequency muscle stimulation: contractile and biochemical alterations. $J$ Appl Physiol 1987;62:2075-2082.

14. Milner-Brown HS, Stein RB, Yemm R: The orderly recruitment of human motor units during voluntary isometric contractions. J Physiol 1973;230:359-370.

15. Morrissey MC, Brewster GE, Shields CL, Brown M: The effects of electrical stimulation on the quadriceps during postoperative knee immobilization. Am J Sports Med 1985;13: 40-45.

16. Vanderthommen M, Kelleter B, Crielaard JM: Détermination de la fréquence de stimulation produisant la contraction tétanique maximale du quadriceps fémoral, in Pelissier J, Roques CF (eds): Electrostimulation des Nerfs et des Muscles. Paris, Masson, 1992, pp 33-37.

17. Warmolts JR, Engel WK: Correlation of motor unit behaviour with histochemical myofiber type in humans by open-biopsy electromyography, in Desmedt JE (ed): New Developments in Electromyography and Clinical Neurophysiology, Basel, Karger, 1973, pp 35-40. 